\title{
Influence of packaging design parameters on customers' decision-making process
}

\section{ABSTRACT}

Many recent research has focused on graphic design and shape of the packaging, and their effects on the customer's decision-making process as two separate categories. Since the shape of the packaging along with the graphic design plays an important role in the visual appearance of the packaging and attracts the customer's attention, the main objective of this research was to find out which packaging shapes and graphic elements customers find most attractive, as well as to understand the general opinion of customers about the influence of packaging aesthetics on their decision-making process when purchasing a product. Methodology of this research was conducted in two stages, from which the first one included creating three different graphic design solutions combined with three shape categories, and three variations of added value, for the same food packaging. The second part of the research covered an online questionnaire, in which a group of 50 people participated. This questionnaire focused on three variables: graphic design of the packaging, packaging shape and it's added value. These variables were evaluated using the Likert scale. Through the questionnaire, participants were asked to answer general questions about the impact of the packaging visual appearance and added value, on their decision-making process when buying a product, as well as to choose the most appealing packaging between the given options. The research results showed that customers preferred non-standard packaging shapes and simple graphic design, as well as packaging with added value. The results of this research prove that the aesthetics of packaging has an impact on the customer's perception of a product, which means that packaging plays an important role in product marketing.

\section{Minja Malešević (B) Mladen Stančić}

University of Banja Luka, Faculty of Technology, Department of Graphic Engineering, Banja Luka, Bosnia and Herzegovina

Corresponding author: Minja Malešević e-mail:malesevicminja@gmail.com

First recieved: 14.6.2021

Accepted: 5.10.2021.

\section{KEY WORDS}

packaging, graphic design, consumer research, marketing

\section{Introduction}

The basic function of packaging is to "preserve product integrity" by protecting the actual food product from potential damage due to "climatic, bacteriological and transportation hazards" (Stewart, 1995), as well as to ensure proper storage and to communicate with customers by providing information about the contents (Robertson, 2012). However, the importance of packaging has increased rapidly in recent years, and in addition to its main functions, packaging plays an important role in attracting customers' interest by increasing their visibility through form and design (Wells, Farley \& Armstrong, 2007). According to Giovanneti (1995) cited by Franken (2020), the biggest challenge for designers and companies is to find the optimal design that is preferred by customers and increases recognition in the market. Since packaging can be considered as the medium between the customer and the product and is the first contact with the consumer, it is clear that packaging plays an 
important role in persuading the customer. Customers tend to make decisions about the product based on the quality of the packaging, i.e. if the packaging gives the impression of inferior quality, consumers will perceive this as if the product is of inferior quality, even if this is not the case (Underwood, Klein \& Burke, 2001). The importance of packaging is constantly increasing due to the ever increasing competition, which means that the product needs to stand out from all other similar products (Morgan, 2016). With this in mind, companies are opting to use various visual techniques to increase customer attention, such as using original materials, shapes and colors for their packaging (Ooijen et al., 2016).

According to Poslon, Kovačević \& Brozović (2021), the form of packaging varies depending on the purpose and type of product. Packaging shape not only makes a product more attractive, but can also help consumers predict the volume of the product, and it can also influence the perception of the taste of a product, as the sense of taste can be activated even without consuming the product. The importance of packaging shape also makes itself felt in differentiating products from competitors, as it can trigger emotions and purchase behavior. The more complex and atypical the shape is, the more attention it attracts (Vladić et al., 2015).

Packaging design is often used as a marketing tool to achieve marketing objectives and meet consumer demands. This can be achieved by using the aesthetic and functional components of a packaging. Aesthetic considerations refer to the shape and size, material, colour, text, and graphics of a packaging. Packaging design is not only critical to branding, but also to the function of the packaging. From a marketing perspective, packaging must meet a number of objectives within a marketing strategy: innovative design to attract customer attention, brand identification, facilitation of product transportation and protection of contents, ease of opening and closing, clever dispensing and recallability (Rundh, 2013).

\section{Problem statement}

It is known that the role of product packaging is multifaceted. Not only it protects the product, but also transmits the information about the product through its visual elements. Therefore, graphic design of visual packaging elements is one of the most effective means of shaping the aesthetics of a product packaging and attracting the consumer attention. Aesthetic food packaging has a greater chance of eliciting positive responses from consumers, in comparison with standardized packaging (Kovačević, Brozović \& Banić, 2020).

Another important aspect of the packaging that is responsible for the visual identity of the packaging is its shape. Even though the shape of the packaging is usually determined by various factors such as material costs, production and transportation, brand characteristics and product requirements, the shape of the packaging plays an important role in communication. The shape and size of the packaging have a great impact on the customer's decision-making process and can attract or deter them (Bata et al., 2018). People tend to perceive the visual aspects of packaging differently, and all of them trigger different emotions and associations that consumers directly associate with the product. Based on this premise, we hypothesized that packaging design and shape, together with it's added value have an important influence on how customers perceive a specific product. With this in mind, this study focused on investigating the relationship between packaging aesthetics and its impact on consumers' emotions and decision-making process.

\section{Methodology}

\section{Samples}

For this research, three different graphic design solutions and shape categories were created for a fictitious biscuit brand, Cakers. The different packaging shapes were created using the software Engview Packaging Design, while the graphic design solutions were created using Adobe Illustrator. The packaging shapes used in this study are triangular (Figure 1), pentagonal (Figure 2) and square (Figure 3).

The graphic solutions used the standard brand colors (yellow, brown, white) in all three solutions. All the designed solutions also included an image of the biscuit and the main elements of the food product's packaging, such as the brand name, the product description, the weight, the bar code, the nutritional tables, the expiry date, etc.

For the first graphic solution, yellow was used as the primary color, occupying half the height of the packaging. The yellow background is covered with brown round shapes, symbolizing the chocolate chips contained in the cookies. The second graphic solution consists of a neutral beige background covered with yellow and white round shapes. The basic color (yellow) was also used as the background color in the third graphic solution. In this case, the yellow color is used as a background for the white cross-line pattern, which is located in the lower part of the packaging. The first and second design solutions differ from the third in additional features that might be of interest to customers. Namely, the first solution is a multisensory packaging, as customers have the opportunity to smell the product contained in the packaging, by rubbing the image of the biscuit on the front of the packaging. The second graphic solution, in addition to the basic elements, also includes elements 

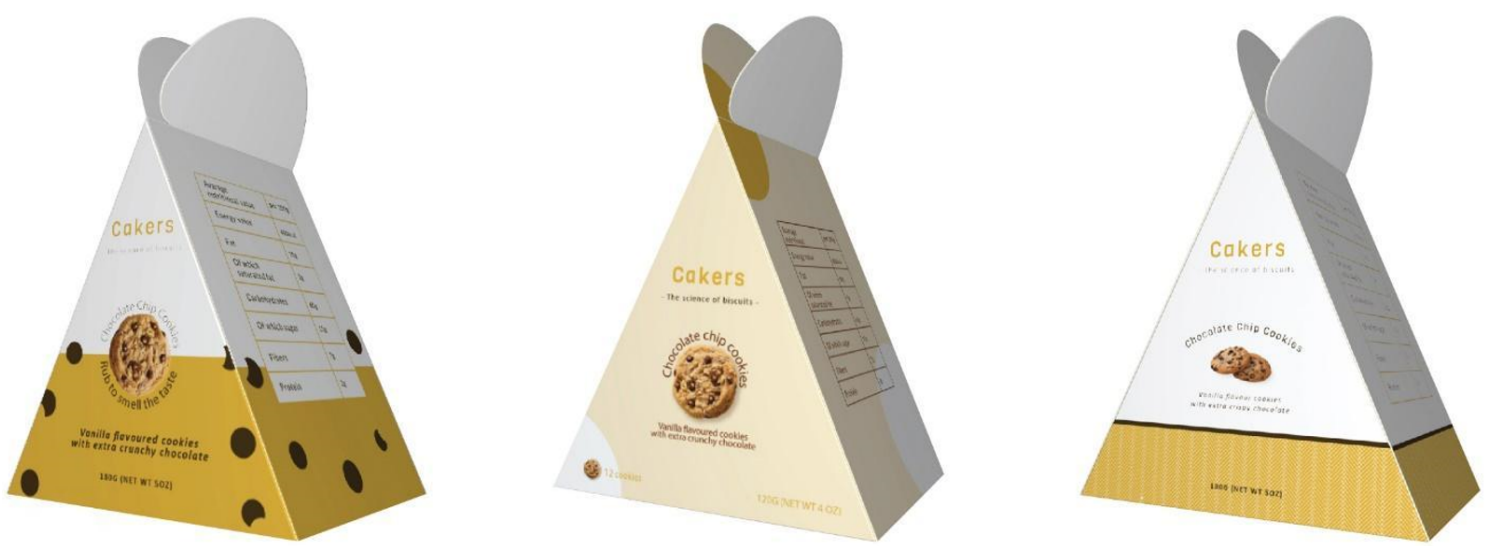

» Figure 1: Triangular packaging in three different graphic designs
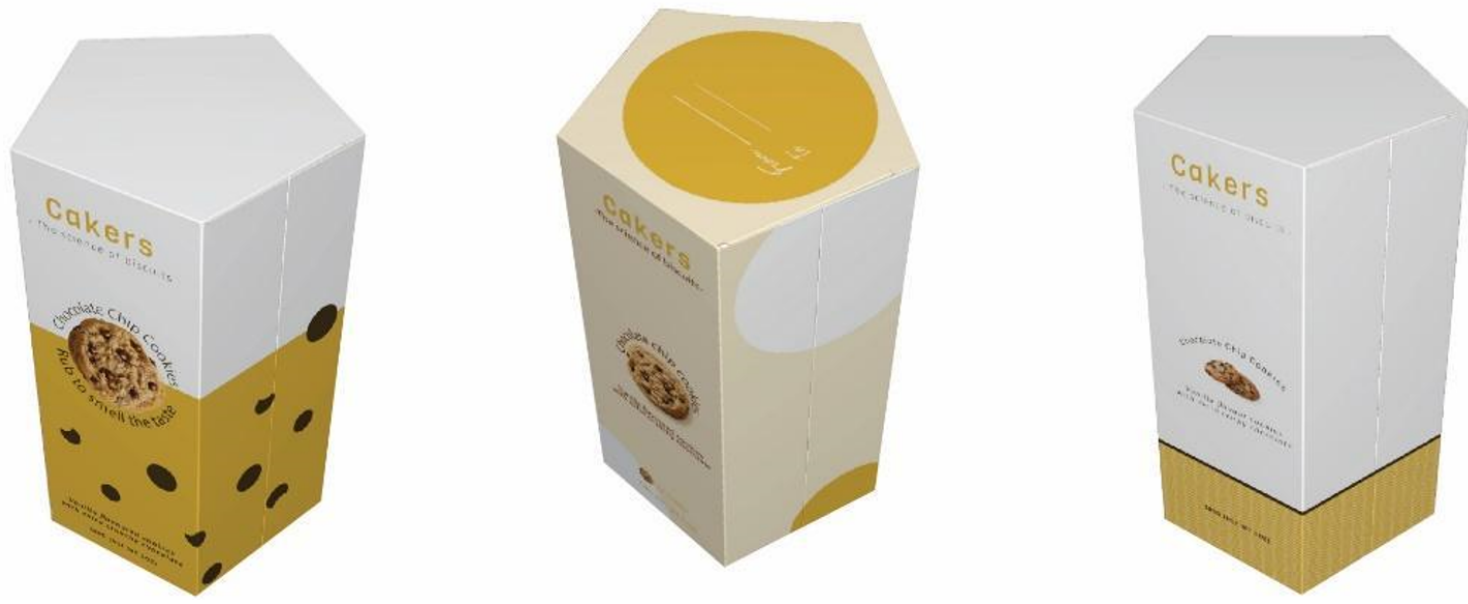

» Figure 2: Pentagonal packaging in three different graphic designs
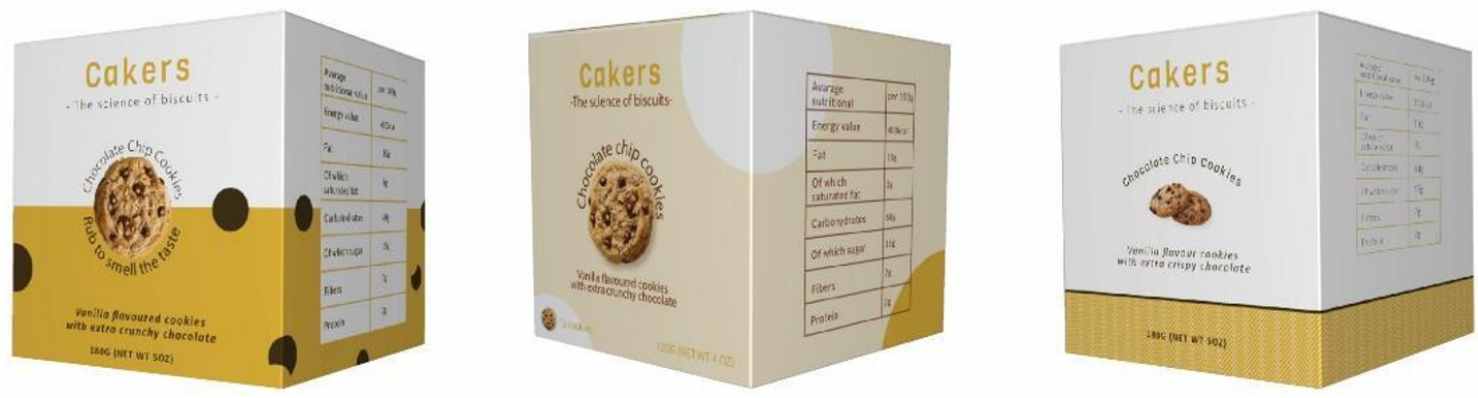

» Figure 3: Square packaging in three different graphic designs

for personalization, on which it is possible to write for whom the packaging or product is intended. All graphic solutions were applied to all three packaging forms.

\section{Participants and procedures}

The research was conducted using an online questionnaire Google Forms in which 50 participants were asked to rate the attractiveness of each packaging on a scale of 1 to 5 and to answer several questions about the overall influence of the packaging on their decision-mak- ing process. $60 \%$ of the participants were women, the rest were men in the age group of 25 to 35 years.

\section{Results}

In order to investigate whether the appearance of the packaging influences the decision-making process of customers when buying a product, participants were asked to answer the question "Do you pay attention to the packaging when buying a product?". 


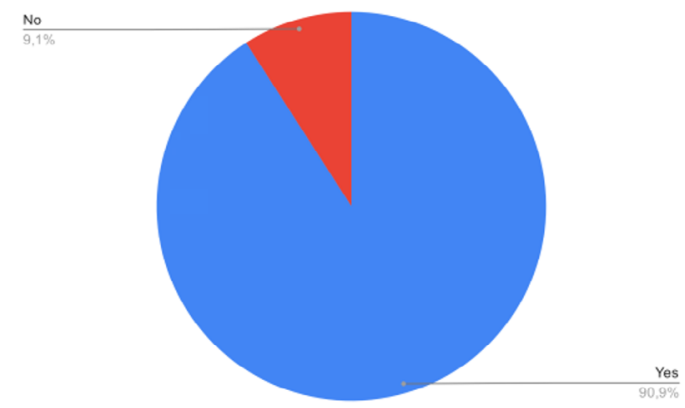

» Figure 4: Ratio of participants who pay attention to the packaging when buying a product

To understand the value that the visual design of the packaging has for the customers, the participants were asked to answer the question "How important is the visual design of the packaging for you?". 40.9\% of participants answered that visual design is moderately important, $27.3 \%$ answered that visual design is important to them, while $31.8 \%$ of participants answered that visual design of packaging is very important to them when they purchase a product (Figure 5). As with the previous question, most of the participants who think that the visual design of the packaging is important were women.

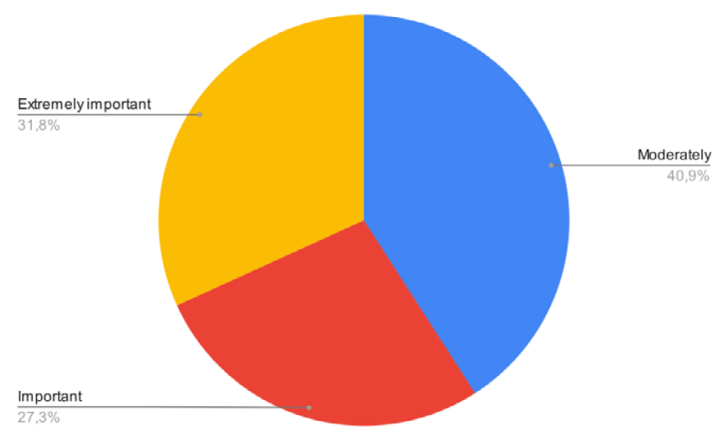

» Figure 5: Ratio of participants with regard to the importance of the visual design of the packaging

Since the first and second biscuit packaging are packaging with additional functions (possibility of personalizing the packaging and multisensory packaging), participants were asked to answer the questions "Do you find packaging with the possibility of personalization interesting?" and "Do you find multisensory packaging interesting?". All participants answered "Yes" to the first question (Figure 6), while $95.8 \%$ of them answered "Yes" and $4.2 \%$ answered "No", to the second question (Figure 7).

After answering these general questions about the visual appearance of the packaging, participants were asked to choose the one they found most visually appealing among the given packaging shapes (triangular, pentagonal, square). $39.1 \%$ of the participants chose the pentagonal shape as the most visually appealing, while $34.8 \%$ chose the standard square shape and $26.1 \%$ of them chose the triangular shape (Figure 8).

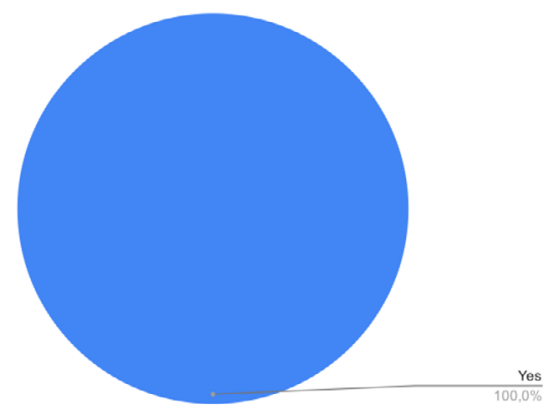

» Figure 6: Ratio of participants' interest in the possibility of personalizing packaging

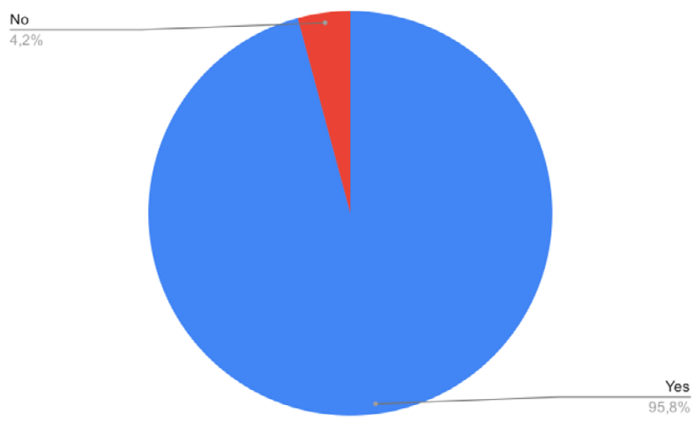

» Figure 7: Ratio of participants' interest in multisensory packaging

In addition to choosing between the given packaging forms, participants were asked to select the one they found most visually appealing among the given graphic solutions (Figure 9). $52.5 \%$ of the participants chose the second graphic solution as their favorite, $39.1 \%$ preferred the first graphic solution, while $8.7 \%$ of the participants chose the third graphic solution as their favorite.

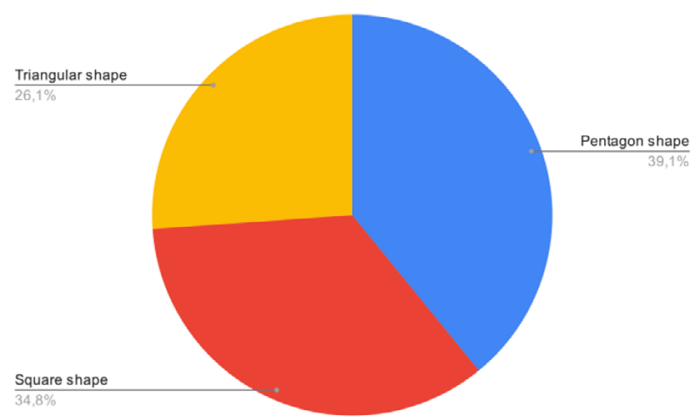

» Figure 8: The participants' choice of the most visually attractive form of packaging

\section{Discussion}

According to the participants, the most attractive combination of graphic design and packaging shape is the pentagonal packaging with the second graphic design solution, which also offers the possibility of 

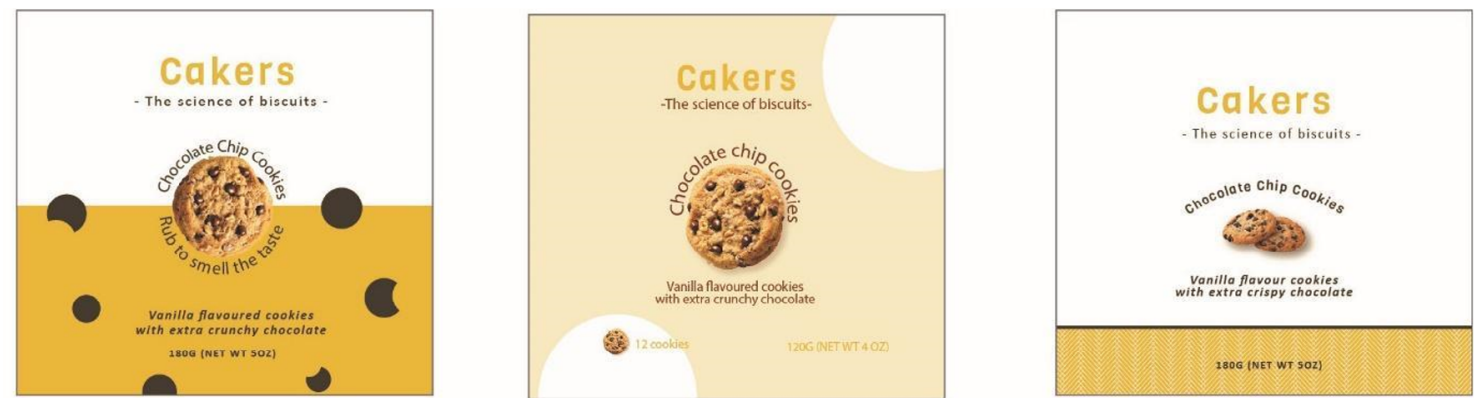

» Figure 9: Graphic design solutions for biscuit packaging

personalization (Figure 10). This research showed that aesthetics have an impact on customers' perception of the packaging and their decision-making process. Another interesting result was that customers find packaging with additional functions more attractive and interesting than packaging without additional functions. The results on the packaging shape chosen showed that customers found non-standard cookies packaging shapes such as pentagonal more visually appealing. According to the participants, the simple graphic design with a soft color palette and an appealing cookie image was more attractive than the line cross pattern and the symbolic chocolate chip illustration.
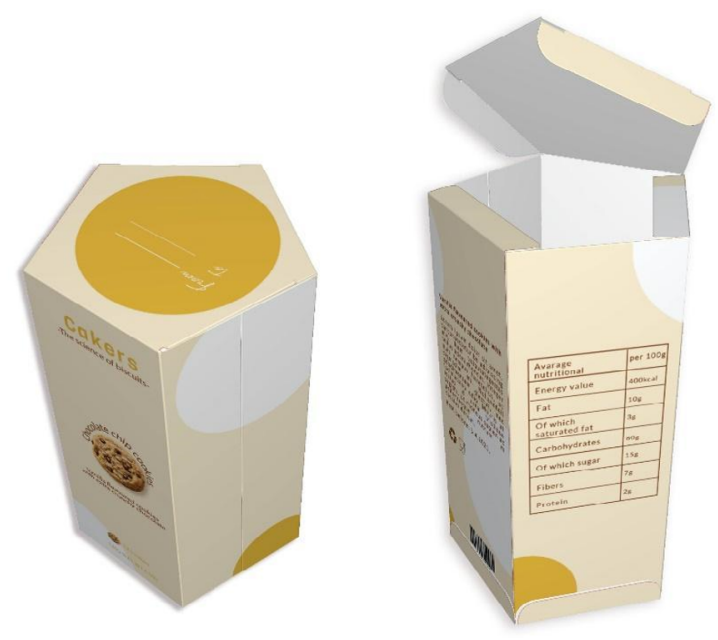

» Figure 10: Most visually appealing graphic design and shape of the biscuit packaging, in the opinion of the participants

\section{Conclusion}

In conclusion, this research shows that the visual appearance of packaging plays an important role in successful marketing. It was noticed that soft color palette, simple geometric shapes and appealing product photographs are more appealing than abstract patterns and symbolic images. Non-standard geometric shapes attract customers' interest more than standard shapes. The results of this research also show that packaging with added value, especially packaging with the possibility of personalization, is very attractive. All these findings can be used as guidelines for food packaging design. Although the research conducted provides important information on visual guidelines for packaging, it should be noted that some results might be different in different age groups and for different products, as the research was conducted on a limited age group between 25 and 35 years and on a single food product (cookie). Considering this, there is a possibility that the participants were subjective due to their general (dis)preference for the product. It should also be noted that participants were surveyed via an online questionnaire, which may be limited due to differences in color representation on screens. Further studies on different foods and in different age groups are planned to further investigate the current results.

\section{References}

Bata, J., Hanzer Jamnicki, S., Banić, D. \& Brozović, M. (2018) Compression resistance of small paperboard packaging shapes. In: Kašiković, N. (Ed.) Proceedings - The Ninth International Symposium on Graphic Engineering and Design, GRID 2018, 08-10 November 2018, Novi Sad, Serbia. Novi Sad, Faculty of Technical Sciences. pp. 237-242.

Franken, G. (2020) Packaging design and testing by eye tracking. In: Dedijer, S. (Ed.), Proceedings - The Tenth International Symposium on Graphic Engineering and Design, GRID 2020, 12-14 November 2020, Novi Sad, Serbia. Novi Sad, Faculty of Technical Sciences. pp. 347-354.

Kovačević, D., Brozović, M. \& Banić, D. (2020) Applying graphic design principles on tea packaging, In: Dedijer, S. (Ed.), Proceedings - The Tenth International Symposium on Graphic Engineering and Design, GRID 2020, 12-14 November 2020, Novi Sad, Serbia. Novi Sad, Faculty of Technical Sciences. pp. 571-575. Morgan, T. (2016) Visual Merchandising. London, Laurence King Publishing.

Ooijen, I., Fransen, M. L., Verlegh, P. W. J. \& Smit, E. G. (2016) Atypical food packaging affects the persuasive impact of product claims. Food Quality and Preference. 48 (A), 33-40. Available from: doi: 10.1016/j.foodqual.2015.08.002. 
Poslon, S., Kovačević, D. \& Brozović, M. (2021) Impact of packaging shape and material on consumer expectations. Journal of Graphic Engineering and Design. 12 (2), 39-44. Available from: doi: 10.24867/JGED-2021-2-039.

Robertson, G. L. (2012) Food Packaging: Principles and Practice. Boca Raton, CRC Press.

Rundh, B. (2013) Linking packaging to marketing: how packaging is influencing the marketing strategy. British Food Journal. 115 (11), 1547-1563. Available from: doi: 10.1108/BFJ-12-2011-0297.

Stewart, B. (1995) Packaging as an Effective Marketing Tool. Surrey, Pira International.

Underwood, R. L., Klein, N. M. \& Burke, R. R. (2001) Packaging communication: attentional effects of product imagery. Journal of Product \& Brand Management. 10 (7), 403-422. Available from: doi: 10.1108/10610420110410531.

Vladić, G., Kecman, M., Kašiković, N., Pal, M. \& Stančić, M. (2015) Influence of the shape on consumers' perception of the packaging attributes. Journal of Graphic Engineering and Design. 6 (2), 27-32.

Wells, L. E., Farley, H. \& Armstrong, G. A. (2007) The importance of packaging design for own-label food brands. International Journal of Retail \& Distribution Management. 35 (9), 677-690. Available from: doi: 10.1108/09590550710773237.

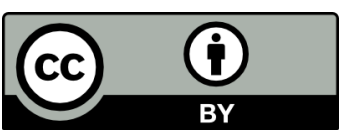

(C) 2021 Authors. Published by the University of Novi Sad, Faculty of Technical Sciences, Department of Graphic Engineering and Design. This article is an open access article distributed under the terms and conditions of the Creative Commons Attribution license 3.0 Serbia (http://creativecommons.org/licenses/by/3.0/rs/). 